\title{
Clinical effects and safety of treating diabetic macular edema with intravitreal injection of ranibizumab combined with retinal photocoagulation
}

\author{
This article was published in the following Dove Press journal: \\ Therapeutics and Clinical Risk Management \\ 5 April 2016 \\ Number of times this article has been viewed
}

\section{Panshi Yan \\ Cheng Qian \\ Wenzhan Wang \\ Yi Dong \\ Guangming Wan \\ Yue Chen}

Department of Ophthalmology, The First Affiliated Hospital of Zhengzhou University, Zhengzhou, People's

Republic of China
Correspondence: Panshi Yan Department of Ophthalmology, The First Affiliated Hospital of Zhengzhou University, No I, Jianshe East Road, Zhengzhou 450052, People's Republic of China

Email yanpsyps@I63.com
Background: This study was designed to examine the clinical effects of treating diabetic macular edema with an intravitreal injection of ranibizumab in combination with retinal photocoagulation.

Methods: Sixty-two cases (75 eyes) with confirmed severe proliferative diabetic retinopathy or proliferative diabetic retinopathy in combination with macular edema were randomly divided into the observation group ( 37 eyes were given an intravitreal injection of ranibizumab combined with retinal photocoagulation) and the control group (38 eyes received retinal photocoagulation only). Vision, fundus condition, central macular thickness, and the macular leakage area were recorded before and after treatment.

Results: The best-corrected visual acuity and macular leakage area were similar between the observation and control groups $(P>0.05)$. The best-corrected visual acuity in the observation group was higher than that in the control group 3 and 6 months after treatment $(P<0.05)$ and showed a rising tendency. The macular leakage area in the observation group was significantly lower than that in the control group 1 and 3 months after treatment $(P<0.05)$. However, the macular leakage area was similar 6 months after treatment $(P>0.05)$. The central macular thickness of the observation group was lower than that in the control group 1, 3, and 6 months after treatment $(P<0.05)$. The laser energy used in the observation group was also smaller than that in the control group $(P<0.05)$. The intraocular pressure was not significantly different between the groups $(P<0.05)$. No patients in the two groups developed eye or systemic complications, such as glaucoma, cataract, or vitreous hemorrhage during treatment.

Conclusion: Intravitreal injection of ranibizumab combined with retinal photocoagulation was proven to be effective in treating diabetic macular edema as it improved vision and resulted in fewer complications.

Keywords: vitreous body, ranibizumab, photocoagulation, diabetic macular edema

\section{Introduction}

Diabetic retinopathy (DR) involves multiple complications. Diabetic macular edema (DME) is the most common complication and one of the leading causes of visual impairment and blindness. ${ }^{1} \mathrm{DME}$, which may occur at any stage of DR, is more likely to occur when people develop severe DR. Besides blood sugar control, retinal photocoagulation can also be used for the treatment of DME. Retinal photocoagulation is found to be weak at improving vision, although it can effectively relieve DME with a lasting curative effect. ${ }^{2}$ One study ${ }^{3}$ found that patients with DME whose blood sugar 
was strictly controlled still had impaired vision 2-3 years later, although they underwent macular focal/grid pattern laser photocoagulation. Therefore, it is necessary to search for a new effective therapy considering the insignificant effect of therapies for treating macular edema.

As research on the mechanism of maculopathy becomes more extensive, some experts ${ }^{4,5}$ have found that vascular endothelial growth factor (VEGF) is an important endogenously mediated factor in the pathogenesis of DR and DME; anti-VEGF drugs only function through the above mechanism. This finding offers a new approach for DME treatment. However, the widely applied anti-VEGF drugs represented by ranibizumab still have defects such as a short half-life, short action time, and repeated injections, causing a great burden on the patients. ${ }^{6,7}$ Anti-VEGF drugs in combination with retinal photocoagulation can reduce repeated treatment times and improve vision; however, such combined treatment is seldom reported in the People's Republic of China and abroad. ${ }^{89}$ The present study only fills the gaps in this aspect. We compared the curative effect and safety of treating DME with an intravitreal injection of ranibizumab combined with retinal photocoagulation and retinal photocoagulation alone to provide detailed and accurate references for clinical treatment.

\section{Materials and methods Research participants}

Seventy patients with DME (83 eyes) who received treatment at the First Affiliated Hospital of Zhenzhou University, People's Republic of China from March 2013 to May 2014 were recruited into this study. This study was approved by the medical ethics committee of the First Affiliated Hospital of Zhengzhou University and all patients signed an informed consent form before treatment. The registration number of this clinical trail was FCC20150521YPS. Patients who were confirmed to have severe nonproliferative DR or proliferative DR combined with macular edema by fluorescence fundus angiography (FFA) and optical coherence tomography were included in the study, while those who developed vitreous hemorrhage, glaucoma, had laser eye surgery, or received treatment previously were excluded. Among the $70 \mathrm{DME}$ cases, 41 were male and 29 were female. They were aged from 44 to 77 years (average: $66.3 \pm 7.8$ years) and had diabetes for 4-24 years (average: 14.9 \pm 5.1 ). All of the patients were randomly divided into the observation group (41 eyes) or control group (42 eyes). The differences in the sex, age, and history of diabetes were not statistically significant between the two groups ( $P>0.05)$; therefore, they were comparable.

\section{Retinal laser photocoagulation}

First, macular focal/grid pattern laser photocoagulation was performed using a krypton yellow laser (wavelength: $568 \mathrm{~nm}$ ). The optic disc macular region was exposed to a $100 \mu \mathrm{m}$ spot and was set at a level 1 reaction for 0.1 seconds. A foveal avascular zone with a diameter of $500 \mu \mathrm{m}$ was maintained. The distance between two adjacent spots was maintained that was as long as the diameter of a spot. ${ }^{10}$ Panretinal photocoagulation was also carried out on the area from the grid photocoagulation area to the equatorial region using an neodymium-doped yttrium aluminum garnet laser with a wavelength of $532 \mathrm{~nm}$. A spot close to the posterior pole was set as $200 \mu \mathrm{m}$, while a spot away from the posterior pole was $500 \mu \mathrm{m}$. The spot reaction was set as level 3 , and the exposure time was controlled between 0.1 and 0.2 seconds. The distance between two adjacent spots was maintained as the diameter of a spot as well. The treatment was completed a total of four times. The next treatment was performed 1 week after the previous one. In the first treatment, panretinal photocoagulation and macular focal/grid pattern laser photocoagulation were carried out on the same day. The data from all stages were recorded.

\section{Intravitreal injection of ranibizumab}

Patients in the observation group received an intravitreal injection 1 week before photocoagulation in the operating room. Patients were first narcotized with alcaine, followed by disinfection and draping. A needle was inserted into the area $3.5 \mathrm{~mm}$ behind the corneoscleral limbus below the temple and was perpendicular to the sclerotic surface. Next, $10 \mathrm{~g} / \mathrm{L}$ ranibizumab was slowly injected into the vitreous body. Gentle pressure was applied to the injection spot with an aseptic cotton bud for 1-2 minutes after medicine injection to prevent backflow. The operative eye was smeared with ofloxacin eye ointment and bound. The patients were reexamined 1 month after receiving laser photocoagulation. Those whose measurements showed no decrease in the central macular thickness (CMT) of the fovea were injected with ranibizumab $(10 \mathrm{~g} / \mathrm{L})$ again. The interval between the two injections was 1 month.

\section{Observation index}

\section{Vision record}

Best-corrected visual acuity (BCVA) changes were recorded. Vision expressed in decimals was converted into the logarithm of the minimum angle of resolution (LogMAR) according to the following formula: $\log$ MAR vision $=\lg (1 /$ vision 
expressed in decimals). Improvement, stability, and decline in vision were determined based on the following standards: BCVA improvement for two or more rows was considered as improved vision; BCVA fluctuation within one row was considered stable vision; and a BCVA decrease in two or more rows was considered declined vision.

\section{Change in fundus fluorescein angiography}

Fluorescence fundus angiography changes were evaluated based on the fluorescence leakage area of retinal new vessels (RNVs): complete disappearance of the leakage of RNVs, no fluorescence leakage; disappearance of most of the leakage of RNVs, fluorescence leakage area after treatment lowered by more than $50 \%$; partial disappearance of the leakage of RNVs, fluorescence leakage area after treatment lowered by less than $50 \%$; no disappearance of the leakage of RNVs, fluorescence leakage area the same as or larger than the original scope; bleeding. The leakage of RNVs could not be evaluated if there was bleeding in the vitreous body or retina after treatment.

\section{CMT measurement by optical coherence tomography}

Internal fixation vision and macular central fixation vision were applied during measurement. Six actinomorphic scanning lines centered on the macular central fovea were used for scanning, and the scanning diameter was $6 \mathrm{~mm}$ (macular central area). Every scanning line contained 100 points. The measurement value was recorded, and the average CMT was calculated.

\section{Changes in intraocular pressure}

Intraocular pressure (IOP) was observed before treatment as well as $1,4,8$, and 12 weeks after treatment.

\section{Laser energy}

The laser energy used for retinal photocoagulation was recorded.

\section{Statistical analysis}

SPSS version 19.0 software (SPSS Inc., Chicago, IL, USA) was used for data analysis. The measurement data of both groups were expressed as mean \pm standard deviation (SD). BCVA was expressed as the logarithm of the LogMAR equivalent. The BCVA and CMT of the two groups during the same treatment period were compared by two independent sample $t$-tests. The BCVA and CMT before and after treatment were compared by paired-samples $t$-tests.
Differences were considered to be statistically significant at a $P$-value less than 0.05 .

\section{Results \\ Changes in BCVA}

The BCVA of the observation and control groups was similar before treatment $(P>0.05)$. The BCVA was similar between the observation and control groups 1 month after treatment $(P>0.05)$; however, the BCVA in the observation group was higher than that in the control group 3 and 6 months after treatment $(P<0.05)$. The detailed data are shown in Table 1 and Figure 1.

\section{Comparison of the leakage area of RNVs}

The leakage area of RNVs in the observation group was obviously smaller than that in the control 1 and 3 months after treatment $(P<0.05)$; the difference in the leakage area of RNVs 6 months after treatment was not statistically significant $(P>0.05)$. The detailed data are shown in Table 2 and Figure 2.

\section{Changes in CMT}

The CMT of the observation group was lower than that of the control group 1, 3, and 6 months after treatment $(P<0.05$; Table 3, Figures 3 and 4).

\section{Comparison of laser energy}

The laser energy in the observation and control groups was $180.53 \pm 34.88 \mathrm{~mW}$ and $265.06 \pm 38.85 \mathrm{~mW}$, respectively. The comparison of the laser energy between the groups is shown in Table 4. The laser energy used in the observation group was lower than that in the control group $(P<0.05)$.

\section{Complications and adverse reactions}

Four eyes had increased IOP on the first day of injection (range: 22-27 $\mathrm{mmHg}$; average: $24.3 \pm 2.1 \mathrm{mmHg}$ ) and recovered to normal values after pharmaceutical treatment. Moreover, five eyes were observed to have subconjunctival

Table I Changes in the best-corrected visual acuity of the two groups before and after treatment

\begin{tabular}{|c|c|c|c|c|c|c|}
\hline \multirow[t]{2}{*}{ Time } & \multicolumn{2}{|c|}{$\begin{array}{l}\text { Control } \\
\text { group }(n=32)\end{array}$} & \multicolumn{2}{|c|}{$\begin{array}{l}\text { Observation } \\
\text { group }(n=30)\end{array}$} & \multirow[t]{2}{*}{$t$} & \multirow[t]{2}{*}{$P$-value } \\
\hline & Mean & SD & Mean & SD & & \\
\hline Before & 0.319 & 0.187 & 0.327 & 0.205 & 0.112 & 0.911 \\
\hline Ist month & 0.375 & 0.208 & 0.427 & 0.194 & 0.713 & 0.482 \\
\hline 3rd month & 0.394 & 0.165 & 0.620 & 0.166 & 3.806 & 0.001 \\
\hline 6th month & 0.401 & 0.172 & 0.587 & 0.119 & 3.468 & 0.002 \\
\hline
\end{tabular}

Note: $P$ value was obtained by a performing a Student's $t$ test. $P=0.05$ was considered as the significance level. 


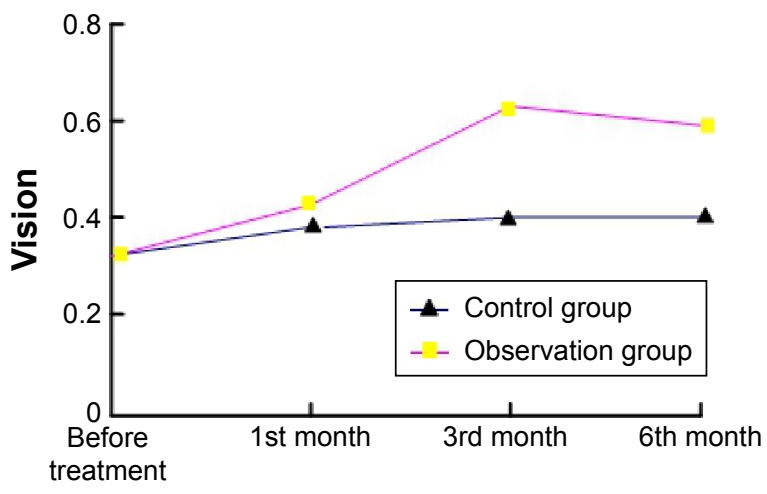

Time

Figure I Changes of vision in the observation group and the control group at different time points.

hemorrhage, and the blood was all absorbed within 2 weeks without any treatment. Severe eye complications, such as glaucoma, newly developed cataract, vitreous hemorrhage, retinal detachment, and infectious endophthalmitis, were not found in either group. Moreover, systemic complications, such as acute hypertension, cerebrovascular accident, myocardial infarction, and thromboembolism related to anti-VEGF drugs, did not occur after the intravitreal injection of ranibizumab.

\section{Repeated treatment}

Three patients in the observation group were examined who had no decrease in CMT 1 month after photocoagulation; all of them agreed to undergo repeated injections. One patient was reinjected with drug twice, and the remaining two patients were reinjected three times (average: $2.70 \pm 0.50$ times). The second injection was performed 1 month after photocoagulation, and the third injection was performed 2 months after photocoagulation. For those cases, follow-up was prolonged to 6 months after the last injection.

\section{Discussion}

With the enhancement in the quality of life of people in the People's Republic of China, there is an increase in the incidence rates of diabetes and DR, which is a diabetic

Table 2 Changes in the leakage area $\left(\mathrm{mm}^{2}\right)$ of retinal new vessels before and after treatment

\begin{tabular}{|c|c|c|c|c|c|c|}
\hline \multirow[t]{2}{*}{ Time } & \multicolumn{2}{|c|}{$\begin{array}{l}\text { Control } \\
\text { group }(n=32)\end{array}$} & \multicolumn{2}{|c|}{$\begin{array}{l}\text { Observation } \\
\text { group }(n=30)\end{array}$} & \multirow[t]{2}{*}{$t$} & \multirow[t]{2}{*}{$P$-value } \\
\hline & Mean & SD & Mean & SD & & \\
\hline & 25.813 & 13.413 & 25.667 & 12.804 & 0.031 & 0.976 \\
\hline Ist month & 18.375 & 8.382 & 12.067 & 7.136 & 2.249 & 0.032 \\
\hline 3rd month & 12.313 & 5.873 & 8.200 & 4.648 & 2.152 & 0.040 \\
\hline 6th month & 5.625 & 5.476 & 5.400 & 4.323 & 0.126 & 0.900 \\
\hline
\end{tabular}

Note: $P$ value was obtained by performing a Student's $t$ test. $P=0.05$ was considered as the significance level.

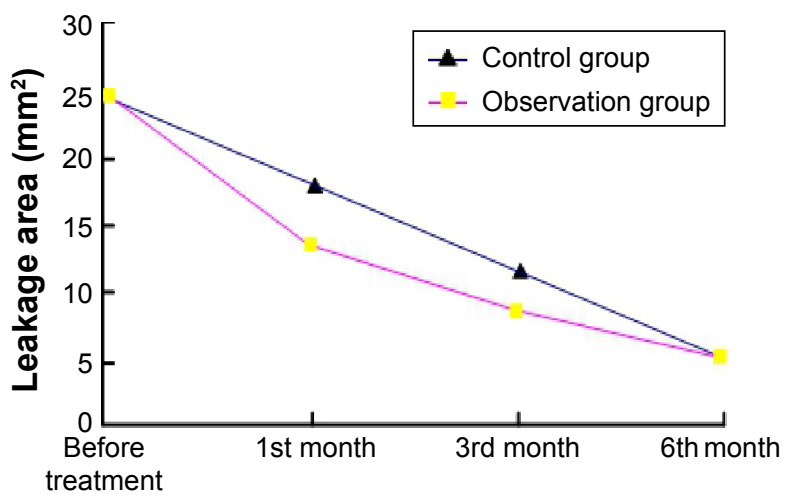

Time

Figure 2 Changes of leakage area of RNV in the observation group and the control group at different time points.

microvascular complication. DME is considered a leading cause of DR. ${ }^{11}$ Previously, macular grid photocoagulation was the major treatment method for macular edema; however, laser photocoagulation alone is of little effectiveness in relieving diffuse edema, and its clinical application is limited by factors such as choice of indication, postoperative recurrence, nonrepeatability of the operation, and complications. ${ }^{12}$ Therefore, drug treatment for macular edema has received much attention in recent years, particularly the intravitreal injection of triamcinolone acetonide. Triamcinolone acetonide action on eye tissue relieves the immune inflammatory reaction by reducing the immune reaction of cells, lowering the permeability of inflammatory vessels, and eliminating particle antigens or amebocytes. However, the intravitreal injection of triamcinolone acetonide is an invasive treatment method, and the technical operation and toxic and side effects of the drug can induce various complications, including an increase in IOP, eye infection, vitreous hemorrhage, and phacoscotasmus. Hence, a more effective and safe treatment method is needed.

Recently, many experts and scholars have further explored the physiopathologic mechanism of DR. It was found that the VEGF levels in the retina and vitreous body are significantly elevated when DR occurs; moreover, macular edema is worsened with increasing VEGF. ${ }^{13}$ Based

Table 3 Comparison of the central macular thickness between the groups at different time points $(\mu \mathrm{m})$

\begin{tabular}{|c|c|c|c|c|c|c|}
\hline \multirow[t]{2}{*}{ Time } & \multicolumn{2}{|c|}{$\begin{array}{l}\text { Control } \\
\text { group }(n=32)\end{array}$} & \multicolumn{2}{|c|}{$\begin{array}{l}\text { Observation } \\
\text { group }(n=30)\end{array}$} & \multirow[t]{2}{*}{$t$} & \multirow[t]{2}{*}{$P$-value } \\
\hline & Mean & SD & Mean & SD & & \\
\hline Before & 509.691 & 57.817 & 502.402 & 57.768 & 0.351 & 0.728 \\
\hline Ist month & 470.689 & 93.701 & 250.732 & 74.679 & 7.196 & 0.000 \\
\hline 3rd month & 450.438 & 84.441 & 220.199 & 35.781 & 9.762 & 0.000 \\
\hline 6th month & 370.561 & 109.632 & 284.732 & 68.790 & 2.590 & 0.015 \\
\hline
\end{tabular}

Note: $P$ value was obtained by performing a Student's $t$ test. $P=0.05$ was considered as the significance level. 


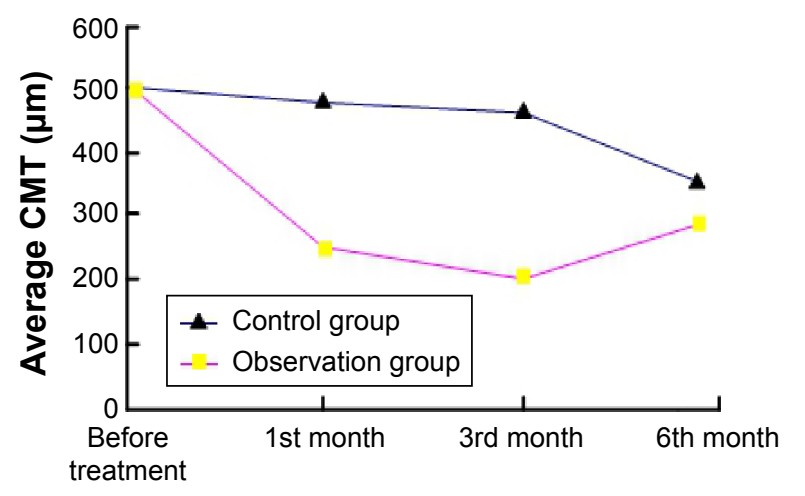

Time

Figure 3 Changes of CMT in the observation group at different time points $(\mu \mathrm{m})$. Abbreviation: CMT, central macular edema.

on these findings, anti-VEGF drugs (eg, ranibizumab) have been gradually applied in the clinical treatment of DME. Ranibizumab, ${ }^{14}$ as an anti-VEGF-A subtype monoclonal antibody with high bioavailability, could restrain neovascularization, lower vascular permeability, and inhibit vascular leakage; it is not known to be toxic in the retina. However, the wide application of ranibizumab is limited due to deficits, such as a short action time, repeated operation, and a high price. Therefore, the authors of this paper developed a DME treatment strategy by combining ranibizumab and laser photocoagulation and compared the treatment strategy with laser photocoagulation.

The research results obtained in this study demonstrated that intravitreal injection of ranibizumab could relieve macular edema and improve vision; after a certain period, most of the patients had reduced CMT and improved vision. However, some cases in the observation group (10\%) recurred or had no relief after treatment. Nevertheless, the reinjection of ranibizumab was proven to be effective upon reexamination. The CMT of the observation group was elevated again 6 months after treatment but was still lower than that of the control group, a finding that was thought to be correlated with the metabolism of ranibizumab in the vitreous cavity. A study ${ }^{15}$ suggested that $4 \mathrm{mg}$ of ranibizumab can be absorbed by the human body 3 months after injection, indicating that the action time of ranibizumab is $\sim 3$ months. In this study, the recurrence appeared 6 months after treatment, and the CMT was increased in the observation group 6 months after treatment, indicating that the intravitreal injection of ranibizumab in combination with laser photocoagulation can delay the recurrence of edema.

Moreover, it was also found that the vision of patients in the observation group showed different levels of improvement; on average, vision showed a rising tendency of improvement within 6 months after treatment. The improvement in
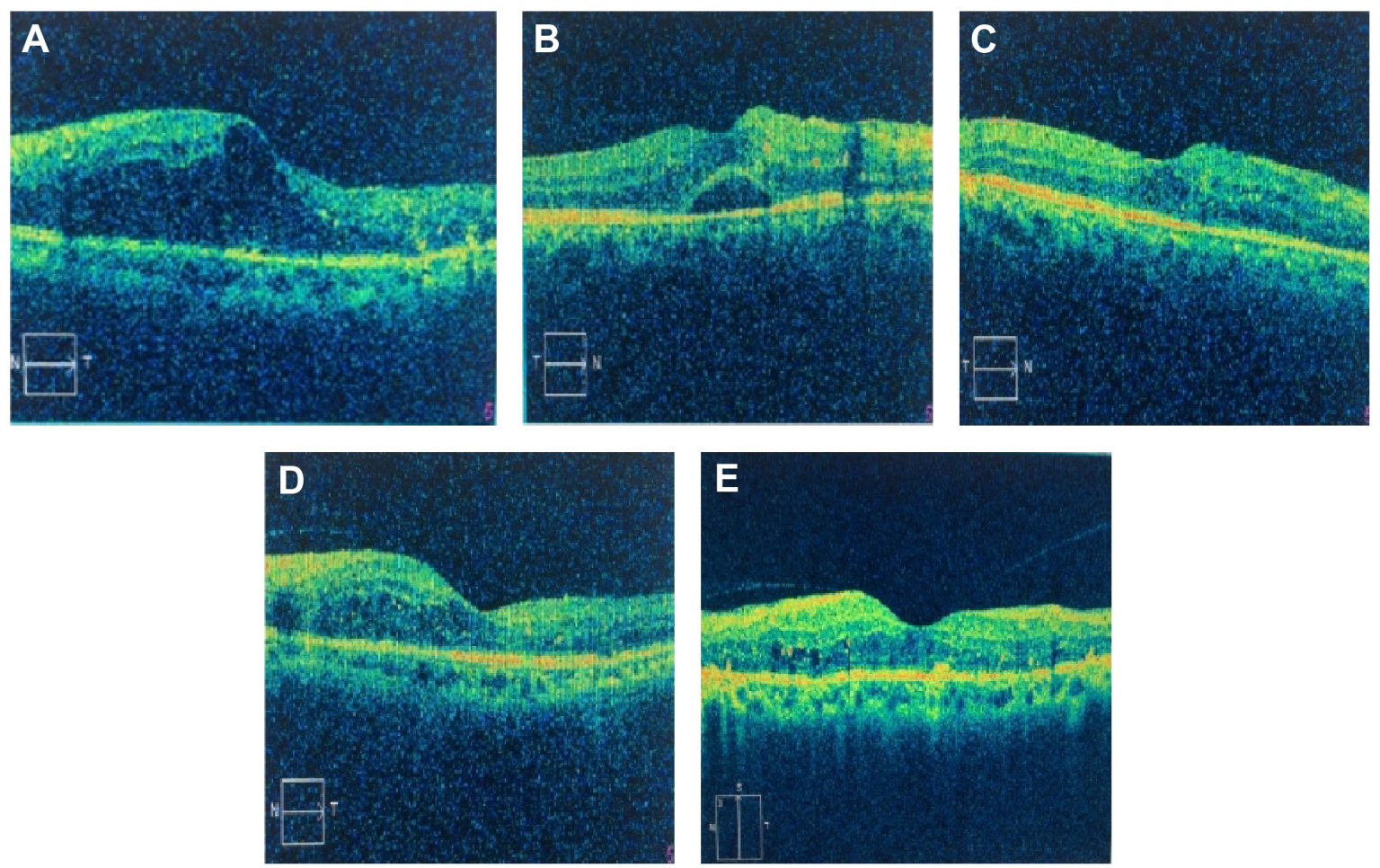

Figure 4 Changes of CMT in the observation group and the control group.

Notes: $\mathbf{A}$ is before combined treatment; $\mathbf{B}$, is after one month after retinal photocoagulation; $\mathbf{C}$ is six months after retinal photocoagulation; $\mathbf{D}$ is after one month combined treatment; and $\mathbf{E}$ is six months after combined treatment.

Abbreviation: CMT, central macular edema. 
Table 4 Comparison of the laser energy between the two groups $(\mathrm{mW})$

\begin{tabular}{llllll}
\hline Group & $\mathbf{n}$ & Mean & SD & $\boldsymbol{t}$ & $\boldsymbol{P}$-value \\
\hline Control group & 32 & 265.06 & 38.85 & 6.36 & 0.000 \\
Observation group & 30 & 180.53 & 34.88 & & \\
\hline
\end{tabular}

Note: $P$ value was obtained by performing a Student's $t$ test. $P=0.05$ was considered as the significance level.

vision was most obvious 3 months after treatment; the vision of some patients declined 6 months after treatment compared with 3 months after treatment, but there was still a significant difference in vision before treatment $(P<0.05)$. The vision variation tendency was consistent with CMT. Three months after treatment, the CMT was the lowest, and vision improvement was the most obvious in the observation group. Vision was worsened 6 months after treatment and strongly correlated with the retention time of ranibizumab in the vitreous body. The control group showed no significant improvement in vision, a finding that was considered to be correlated with the slow relief of macular edema. All of the findings suggest that macular edema is the direct cause of the vision decline in DME patients, and vision can be improved as edema is gradually relieved. This conclusion is similar to the research results of a previous study. ${ }^{16}$

The curative effect was the most significant 3 months after injection, but some patients had an abnormal CMT and an average vision of $0.620 \pm 0.166$. Thus, the edema was completely absorbed, and vision impairment caused by edema was not thoroughly relieved. Among all of the patients in this study, six eyes recurred in 6 months to 1 year after treatment, suggesting that the drug can only relieve macular edema temporarily rather than permanently eradicate it.

The leakage area of the RNVs in the two groups showed an obvious decline after treatment. The difference between the two groups was statistically significant 1 and 3 months after treatment $(P<0.05)$, but no significant difference was found 6 months after treatment $(P>0.05)$. We thought that drug injection 1 week before laser photocoagulation effectively restrained the growth of RNVs and accelerated the fading of RNVs. These findings are similar to the conclusion that ranibizumab can inhibit the generation of new vessels and promote fading. ${ }^{17}$

Laser photocoagulation carries certain risks. The improper use of laser energy may result in a narrowed view, night blindness, and dyschromatopsia. Laser photocoagulation can also cause macular edema and central vision impairment. ${ }^{18,19}$ In our study, the laser energy values in the observation and control groups were $180.53 \pm 34.88 \mathrm{~mW}$ and $265.06 \pm 38.85 \mathrm{~mW}$, respectively, and the difference was statistically significant $(P<0.01)$. Vascular leakage can induce edema. Severe edema requires treatment with high-laser energy, but the damage to the retina is also great. Drug injection 1 week before laser photocoagulation effectively inhibited the growth of RNVs, reduced vascular leakage, and relieved retinal edema, thereby lowering the laser energy required, protecting the functions of the retina and reducing the incidence of complications. As a result, vision was improved in the observation group 1 month after laser photocoagulation, was improved significantly after 3 months, and was slightly elevated after 6 months. In contrast, the control group only showed little improvement, and the improvement in a few cases might be correlated with retinal edema, exudation, absorption of blood, and a reduced leakage area of the RNVs. ${ }^{20}$

\section{Conclusion}

In summary, laser photocoagulation or laser photocoagulation combined with the intravitreal injection of ranibizumab can relieve DME and prevent a further decline in vision. However, the combined therapy causing fewer complications was proven to be more effective and helpful in guiding clinical treatment. The study also had some limitations. The sample size was small, and the follow-up time was relatively short. Furthermore, the formulations of the next therapy for DME patients who show no improvement after treatment, as well as the curative effect, have not been discussed. Multicentre, long-term, and large sample-sized randomized controlled trials remain to be carried out in the future to further confirm the long-term curative effect and safety of the combined therapy.

\section{Disclosure}

The authors report no conflicts of interest in this work.

\section{References}

1. Yau JW, Rogers SL, Kawasaki R, et al. Global prevalence and major risk factors of diabetic retinopathy. Diabetes Care. 2012;35(3):556-564.

2. Perente I, Alkin Z, Ozkaya A, et al. Focal laser photocoagulation in non-center involved diabetic macular edema. Med Hypothesis Discov Innov Ophthalmol. 2014;3(1):9-16.

3. Klein R, Moss SE, Meuer SM, Klein BE. The 15-year cumulative incidence of retinal vein occlusion: the Beaver Dam Eye Study. Arch Ophthalmol. 2008;126(4):513-518.

4. Luo XR, Zheng QX, Li WS. Progress of evidence-based medicine study of central retinal vein occlusion. Chin J Pract Ophthalmol. 2011; 29(2):103-109.

5. Rii T, Itoh Y, Inoue M, Hirakata A. Foveal cone outer segment tips line and disruption artifacts in spectral-domain optical coherence tomographic images of normal eyes. Am J Ophthalmol. 2012;153: 524-529.

6. Zheng Z. Prevention and treatment of diabetic retinopathy: progress, challenges, and future prospects. Chin J Ocul Fundus Dis. 2012;28(3): 209-214. 
7. Nguyen QD, Brown DM, Marcus DM, et al. Ranibizumab for diabetic macular edema: results from 2 phase III randomized trials: Rise and Ride. Ophthalmology. 2012;119(4):789-801.

8. Titchenell PM, Antonetti DA. Using the past to inform the future: antiVEGF therapy as a road map to develop novel therapies for diabetic retinopathy. Diabetes. 2013;62(6):1808-1815.

9. Brown DM, Nguyen QD, Marcus DM, et al. Long-term outcomes of ranbizumab therapy for diabetic macular edema: the 36-month results from two phase III trials RISE and RIDE. Ophthalmology. 2013; 120(10):2013-2022.

10. Hua W, Cao S, Cui J, Maberley D, Matsubara J. Analysis of reasons for noncompliance with laser treatment in patients of diabetic retinopathy. Can J Ophthalmol. 2013;48(2):88-92.

11. Stewart MW. Critical appraisal of ranibizumab in the treatment of diabetic macular edema. Clin Ophthalmol. 2013;7:1257-1267.

12. Srinivasan VJ, Monson BK, Wojtkowski M, et al. Characterization of outer retinal morphology with high-speed, ultrahigh-resolution optical coherence tomography. Invest Ophthalmol Vis Sci. 2008;49(4):1571-1580.

13. Ai H, Yang XG. Expression of VEGF and IL-6 in atria and vitreous cavity of patients with central retinal vein occlusion macular edema. Chin J Cell Mol Immunol. 2011;27:1124-1126.

14. Paulus YM, Gariano RF. Diabetic retinopathy: a growing concern in an aging population. Geriatrics. 2009;64(2):16-20.
15. Nicholson BP, Schachat AP. A review of clinical trials of anti-VEGF agents for diabetic retinopathy. Graefes Arch Clin Exp Ophthalmol. 2010;248(7):915-930.

16. Do DV, Nguyen QD, Khwaja AA, et al. Ranibizumab for edema of the macula in diabetes study: 3-year outcomes and the need for prolonged frequent treatment. JAMA Ophthalmol. 2013;131(2):139-145.

17. Ciulla TA, Criswell MH, Danis RP, Hill TE. Intravitreal triamcinolone acetonide inhibits choroidal neovascularization in a laser-related rat model. Arch Ophthalmol. 2001;119(2):399-340.

18. Benhamou N, Massia P, Haouchine B, Audren F, Tadayoni R, Gaudric A. Intravitreal triamcinolone for refractory pseudophakic macular edema. Am J Ophthalmol. 2003;135:246-249.

19. Lima VC, Yeung L, Castro LC, Landa G, Rosen RB. Correlation between spectral domain optical coherence tomography findings and visual out-comes in central retinal vein occlusion. Clin Ophthalmol. 2011;5:299-305.

20. Mitchell P, Bandello F, Schmidt-Erfurth U, et al. The restore study: ranibizumab monotherapy or combined with laser versus laser monotherapy for diabetic macular edema. Ophthalmology. 2011;118(4) 615-625.
Therapeutics and Clinical Risk Management

\section{Publish your work in this journal}

Therapeutics and Clinical Risk Management is an international, peerreviewed journal of clinical therapeutics and risk management, focusing on concise rapid reporting of clinical studies in all therapeutic areas, outcomes, safety, and programs for the effective, safe, and sustained use of medicines. This journal is indexed on PubMed Central, CAS,

\section{Dovepress}

EMBase, Scopus and the Elsevier Bibliographic databases. The manuscript management system is completely online and includes a very quick and fair peer-review system, which is all easy to use. Visit http://www.dovepress.com/testimonials.php to read real quotes from published authors.

Submit your manuscript here: http://www.dovepress.com/therapeutics-and-clinical-risk-management-journal 